\title{
Prevalencia del dolor músculo-esquelético en los Tecnólogos en Radiología e Imágenes Diagnósticas
}

\author{
Jeniffer Alejandra Castañeda Bedoya', Wilder Andredi Gallo Arias ', \\ Alejandra Vanessa Ramírez Ladino', Leidy Tatiana Rodríguez Calderón', \\ Biviana Mayerly Rúales Rúales ${ }^{1}$
}

Docente Asesor: Mario Andrés Espinosa Acosta²

RESUMEN $\mid$ El propósito de esta investigación es hacer un estudio descriptivo, en el cual se observe la cantidad de Tecnólogos de Radiología de la ciudad de Pereira que presentan dolores músculo esquelético de manera puntual o periódica, en la sala de rayos X convencional. Se utilizarán variables sociodemográficas con el fin de asociar y definir cuál es la principal causa que conlleva al factor de riesgo evaluado; se utilizará como instrumento principal el Nórdico de Kuorinka, que nos permite la detección y análisis de algias músculo esqueléticas que todavía no han constituido enfermedad, reconociendo el riesgo de manera proactiva y precoz.

Dolor Músculo Esquelético;

PALABRAS Tecnólogos en Radiología;

CLAVE Prevalencia Puntual;

Prevalencia Periódica. 


\section{Prevalence of musculoskeletal pain in Radiology and Diagnostic Imaging Technologists}

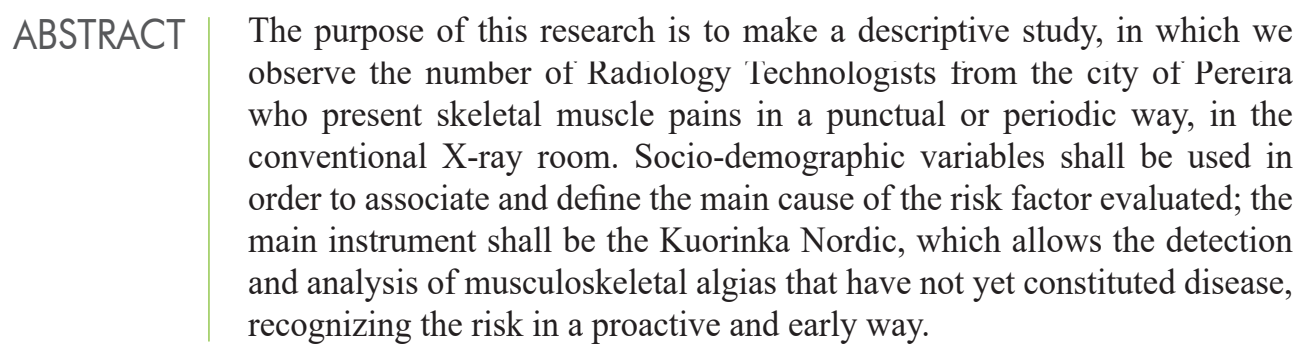

Skeletal Muscle Pain;

Radiology Technologists;

KEYWORDS Punctual Prevalence;

Periodic Prevalence. 


\section{INTRODUCCIÓN}

Los Tecnólogos en Radiología e Imágenes Diagnósticas aseguran la producción y adquisición integral de imágenes biomédicas de excelente calidad, las cuales soportan el diagnóstico clínico y la posterior toma de decisiones médicas. Dentro de su carrera, el Tecnólogo en Radiología puede desempeñar varias funciones, entre las cuales se incluyen el traslado de pacientes inmovilizados y de equipos multidisciplinarios con los cuales se tomarán las imágenes. Para ello, se utilizan movimientos repetitivos que pueden generar dolores músculo esqueléticos, sobre todo en las extremidades superiores, dorso-lumbar y el cuello. Por lo anterior, se pretende determinar la prevalencia del dolor músculo esquelético en los Tecnólogos de Radiología en la sala de rayos X convencional de centros radiológicos de la ciudad de Pereira en el segundo periodo del 2019, y de esta manera identificar los factores de riesgo asociados al trabajo que generan enfermedades y accidentes laborales para prevenirlos e intervenir antes de que dichos síntomas se conviertan en enfermedades o incapacidades laborales.

Se darán algunas definiciones sobre el tema:

> Dolor Músculo Esquelético: es una consecuencia conocida del esfuerzo repetitivo, de la repetición excesiva, que generan trastornos músculo esqueléticos relacionados con el trabajo. Estas lesiones provocan dolor en los huesos, articulaciones, músculos o estructuras circundantes (1).

> Tecnólogo en Radiología: son los trabajadores encargados de la adquisición de imágenes diagnósticas, tanto en radiología convencional, resonancia magnética, medicina nuclear y tomografía axial.

> Prevalencia: la prevalencia describe la proporción de la población que padece la enfermedad en estudio, en un momento determinado (2).

Instrumento Nórdico de kuorinka: este instrumento está estandarizado para la detección y análisis de síntomas músculo esquelético, y su fin es detectar la existencia de síntomas iniciales que todavía no han constituido enfermedad; también nos permite estimar el riesgo de manera proactiva y así poder actuar de forma precoz (3).

\section{MATERIALES Y MÉTODOS}

Se desarrolla un estudio descriptivo transversal en el que observaremos el número de Tecnólogos de Radiología de la ciudad de Pereira que presentan dolores músculo esquelético en la sala de rayos X convencional, utilizando variables sociodemográficas, y como principal instrumento el Nórdico de Kuorinka descrito anteriormente, (4). 
Tipo de estudio: cuantitativo descriptivo de tipo transversal

Población: tecnólogos en Radiología e Imágenes Diagnósticas de un centro radiológico de la ciudad de Pereira.

$>$ Criterios de exclusión: antecedentes de otras enfermedades; Tecnólogas en estado de embarazo.

$>$ Recolección de la información: para la recolección de la información se utilizará un formato escrito de la prueba Nórdica de Kuorinka, el cual se aplicará en un centro radiológico de la ciudad de Pereira.

Análisis de la información: el análisis de la información se realizará a través de la exploración de los datos recolectados por medio del instrumento Nórdico de Kuorinka.

\section{RESULTADOS}

Los resultados que se pretenden obtener de esta investigación, puesto que aún se encuentra en curso, es la descripción de la prevalencia del dolor músculo esquelético que se presenta en los tecnólogos en radiología e imágenes diagnósticas, evaluados a través de instrumentos Nórdico de Kuorinka y variables sociodemográficas, donde obtendremos los riesgos asociados al trabajo de los Tecnólogos en Radiología e Imágenes Diagnósticas, con los cuales evidenciaremos el riesgo evaluado, para promover estrategias de intervención en Salud Ocupacional (5). 
1. Dolor musculoesquelético. 2009 International Association for the Study of Pain (IASP) [Internet]. Iasp-pain.org. 2009 [citado 20 mayo 2019]. Recuperado de:https://www.iasp-pain.org/

2. Ibañez C. No Title [Internet]. Recuperado de: https://www.madrimasd.org/ blogs/salud_publica/2012/02/29/133136

3. Kuorinka I. Cuestionario Nórdico. España; 2014.

4. Pineda Álvarez DM, Carrasco FL, Morales Sanmartín J, Álvarez Pesantez $\mathrm{K}$ del R. Prevalencia de dolor musculoesquelético y factores asociados en odontólogos de la ciudad de Cuenca, Ecuador, 2016. Acta Odontológica Colomb. 2019;9(1):24-36.

5. LuttmannA, Jager M, Griefahn B. Prevención de trastornos musculoesqueléticos en el lugar de trabajo. Ser Prot la salud los Trab [Internet]. 2004;(5):1-30. Recuperado de: http://www.who.int/occupational_health/publications/ muscdisorders/es/ 